\title{
Expectativas e medos de professores em formação: o papel do estágio supervisionado de ensino
}

\author{
Delano Moody Simões da Silva ${ }^{1}$ \\ Ana Júlia Pedreira ${ }^{2}$
}

\begin{abstract}
RESUMO
O estágio supervisionado é desencadeador de uma série de emoções nos estudantes, como expectativas, medos e angustias com relação à sua realização. $\mathrm{O}$ conhecimento desses sentimentos por parte dos formadores de professores poderia ajuda-los na abordagem dos mesmos ao longo do processo de formação, antecipando ou discutindo situações que contribuam para diminuir os possíveis efeitos negativos desses. O objetivo desse estudo foi identificar as expectativas e medos de um grupo de licenciandos em Ciências Naturais, na primeira disciplina de estágio supervisionado e discutir a influência dessa disciplina no enfrentamento desses sentimentos. Os estudantes indicaram mais medos que expectativas no primeiro dia de aula quanto à realização do estágio. A partir da análise de conteúdo percebemos, nas indicações, que o momento de estágio realmente é cercado de muita tensão e apreensão. Enfrentar esses sentimentos no contexto escolar, sob orientação de professores supervisores pode ser determinante para a carreira do futuro professor.
\end{abstract}

PALAVRAS-CHAVE: Formação de Professores. Experiência. Identidade docente. Estágio Supervisionado de Ensino.

Hopes and fears of teachers in training: the role of practicum

\footnotetext{
${ }^{1}$ Doutor em Ecologia. Faculdade UnB Planaltina (FUP), Brasília, DF, Brasil. https://orcid.org/0000-0002-6784-6161. delanomoody@gmail.com.

${ }^{2}$ Doutora em Educação.Universidade de Brasília (UnB), Brasília, DF, Brasil. https://orcid.org/0000-0003-2124-1789. anajuliapedreira@unb.br.
} 


\begin{abstract}
The practicum is the trigger of a lot of emotions in student teachers, the hopes, fears and anguish with regards to its realization. The knowledge of these feelings by teachers' educators could be helpful in approaching these feelings throughout the training process, anticipating or discussing situations that contributing to decrease the possible negative effects. This way, the goal of this study was identifying the hopes and fears of a student teachers' group in Natural Science, on the first practicum course and discussing the influence of this course in coping with these feelingsThe students indicated more fears than hopes in the first-class day. From the analysis of indications, we noticed the practicum moment is surrounded with tension and apprehension. Coping these feelings in the school context with teacher or teacher supervision could be determinant to the career of future teacher.
\end{abstract}

KEYWORDS: Teacher Education. Experience. Terceira palavra. Teacher identity. Practicum.

$$
* * *
$$

\title{
Introdução
}

O componente prático no processo de formação de professores sempre foi alvo de grandes discussões. Existe, no entanto, um consenso que para formar professores precisamos não só abordarmos, junto aos estudantes conceitos, teorias, metodologias e estratégias, mas também é necessário que estes apliquem e validem os conhecimentos em situações reais e a partir dessas experiências reconstruam-os e desenvolvam novos, além de vivenciarem o cotidiano da sua futura profissão, na escola. Para Tardif (2014) esses conhecimentos, ou saberes, que são desenvolvidos ao longo dos cursos de formação inicial de professores necessitam da prática para validálos e aprofundá-los, permitindo que o futuro professor desenvolva seu habitus e construa sua identidade como docente. 
Essa prática ou esses momentos práticos em situações reais, no ambiente escolar, estão previstos nos cursos de licenciatura e são concentrados nas disciplinas chamadas genericamente de estágio curricular supervisionado de ensino (BRASIL, 2015) o qual é compreendido como:

[...] o tempo de aprendizagem que, através de um período de permanência, alguém se demora em algum lugar ou ofício para aprender a prática do mesmo e depois poder exercer uma profissão ou ofício. Assim o estágio curricular supervisionado supõe uma relação pedagógica entre alguém que já é um profissional reconhecido em um ambiente institucional de trabalho e um aluno estagiário (CNE/CP n ${ }^{\circ} 28 / 2001$, p. 10).

Dessa forma o estágio não é apenas a aplicação de conhecimentos, procedimentos ou protocolos, ele é uma experiência na profissão docente, não no sentido de experimentar ou testar algo, mas no sentido de viver a experiência de ser docente sob a supervisão de um profissional da área. Como afirma Larrosa (2011) sobre o papel da experiência na formação docente, ela é um acontecimento, que pode provocar profundas transformações de ser, agir e pensar.

Diante de tantos significados para a carreira docente e para o licenciando, o estágio supervisionado é desencadeador de uma série de emoções nos estudantes, como expectativas, medos e angustias com relação à sua realização (MARTINU; SOUZA; GOMES-DA-SILVA, 2013). Para muitos alunos o momento do estágio é um divisor de águas na sua formação, sentimento esse que pode contribuir, mas também provocar efeitos negativos como ansiedade e insegurança, levando a ser um momento estressante no processo de formação dos futuros professores (CHAPLAIN, 2008). O conhecimento desses sentimentos por parte dos formadores de professores poderia ajuda-los na abordagem dos mesmos ao longo do processo de formação, antecipando ou discutindo situações que contribuíssem para diminuir os seus possíveis efeitos negativos (HONG; GREENE, 2011). 
O curso de licenciatura em Ciências Naturais da Faculdade UnB Planaltina (FUP) forma professores para atuarem na disciplina de Ciências nos anos finais do ensino fundamental. Na grade curricular do curso estão previstos quatro momentos de estágio supervisionado: Estágio Supervisionado de Ensino de Ciências 1, 2, 3 e 4 (ESENC 1, 2, 3 e 4). Cada estágio possui objetivos e atividades específicas conforme descrito em Razuck e Rotta (2014), sendo que o primeiro estágio, ESENC 1, é a primeira inserção do aluno na escola. Na grade curricular esse estágio deve ser realizado a partir do quinto semestre para o curso diurno e no sexto para o curso noturno, ou seja, ao longo terceiro ano de curso (tempo mínimo do curso: diurno 4 anos, noturno 4 anos e meio). Sendo assim quando o aluno chega no período do primeiro estágio ela já adquiriu saberes diversificados da profissão docente (conteúdos específicos de ciências, conteúdos pedagógicos, metodologias de ensino dentre outros), mas ainda não os colocou em prática. Dessa forma, o objetivo desse estudo foi identificar as expectativas e os medos de um grupo de licenciandos em Ciências Naturais, na primeira disciplina de estágio supervisionado e discutir a influência dessa no enfrentamento desses sentimentos.

\section{Fundamentação Teórica}

Nos mais diversos contextos de formação de professores o estágio supervisionado de ensino é tido como um dos momentos mais importantes (BECK; KOSNIK, 2002; BULLOUGH et al. 2002; SMITH; LEV- AKI, 2005; PIMENTA; LIMA, 2006; PARKISON, 2008; BATES; RAMIREZ; DRITS 2009; KOC, 2012, BARRETO; OLIVEIRA; ARAÚJO, 2013; SILVA; PEDREIRA, 2016). Baccon e Arruda (2010) afirmam que passar pelo estágio é de fundamental importância para o licenciando desenvolver o sentimento de "ser professor", permitindo que eles mobilizem e desenvolvam saberes específicos da docência. Esses saberes oriundos da prática da experiência 
comprovam ou afirmam crenças e valores no futuro professor (TARDIF, 2014), possibilitando que esses adquiram mais confiança, superando medos relacionados à carreira docente (TULI, 2009).

Medos e outros sentimentos relacionados ao estágio ou à docência em si são comuns e esperados por parte dos alunos, sendo considerados por alguns autores elementos importantes no trabalho e na construção da identidade docente (VAN VEEN; SLEEGERS; VAN DE VEN, 2005; MARTINU; SOUZA \& GOMES-DA-SILVA, 2013). A origem desses sentimentos é variada, pois pode possuir relação com momentos anteriores à vida acadêmica do licenciando, possivelmente de quando ele era aluno na educação básica (SCHUTZ; CROWDER; WHITE, 2001; LESHEM; TRAFFORD, 2006; HONG; GREENE, 2011). Pode também estar relacionado à concepção que esses estudantes construíram do que é ser um bom professor (SHOYER; LESHEM, 2016) ou simplesmente o medo de falhar ou não dominar algum conteúdo ou estratégia (LIMA, 2010; HONG; GREENE, 2011; MARTINU; SOUZA; GOMES-DA-SILVA, 2013; SHOYER; LESHEM, 2016). Dessa forma, a construção da identidade de um docente é influenciada pela sua experiência enquanto aluno, sua trajetória durante a formação inicial e seu exercício profissional (FEIMAN-NEMSER, 2001; MARCELO, 2010; PEREIRA; OVIGLI, 2017).

Conhecer esses sentimentos e abordá-los de alguma forma ao longo da formação pode contribuir muito na carreira dos futuros professores (SHOYER; LESHEM, 2016; LINDQUIST et al. 2017), já que os estudantes poderão não só vivenciar o cotidiano escolar, durante o estágio, mas principalmente trabalhar esses medos e essas expectativas, (SCHUTZ; CROWDER; WHITE, 2001; ROTTA; FRANÇA, 2018), reafirmando assim o estágio como uma experiência formativa com impactos significativos na vida do futuro professor.

Sobre a experiência na formação docente, Larrosa (2005) afirma que é pessoal, mesmo dois indivíduos passando pela mesma situação e acontecimentos, eles não vivem da mesma forma essa experiência. Segundo 
o autor, nessa experiência o sujeito cai, levanta, tem acertos e erros, mas para aprender com isso ele tem que estar aberto e de certa forma exposto para ela. Como citado por Larrosa a "experiência é o que nos passa, o que nos acontece, o que nos toca" (LARROSA, 2005, p.21).

O estágio supervisionado de ensino se encaixa perfeitamente nessa concepção de experiência, pois uma turma inteira pode realizar o estágio no mesmo momento, mas a experiência de cada um é individual, com erros, acertos e aprendizagens diferenciadas. Essa experiência pessoal do estágio pode ser evidenciada em alguns trabalhos que apresentam relatos dos alunos após o estágio (ZANCUL, 2011; SILVA; PEDREIRA, 2016; ROTTA; FRANÇA, 2018) e que indicam o quanto foi importante e transformador passar por ela.

Nessa perspectiva transformadora Larrosa (2011) ainda afirma que o lugar da experiência não é somente um espaço, um endereço, uma sala, mas sim o próprio sujeito, ou suas ideias, ou suas palavras, seus sentimentos, por isso a ideia de que a experiência seja algo que nos acontece. Após o estágio muitos sentimentos são superados, outros não e muitos novos surgirão, mas esse processo de encontro e reflexão é fundamental para a construção da identidade do licenciando como docente.

\section{Metodologia}

\section{Contexto da pesquisa}

No curso de Licenciatura em Ciências Naturais da Faculdade UnB Planaltina a disciplina de ESENC 1 tem como objetivos: a introdução do aluno no contexto escolar, a observação e o planejamento, juntamente com o professor regente da escola, e a regência de classe do estagiário. No início do semestre os alunos são orientados quanto às atividades que devem desenvolver na disciplina, bem como em relação às questões burocráticas 
referentes ao estágio. Ao longo do semestre eles trazem as discussões e questões emergentes nas suas escolas de estágio, as quais são debatidas em conjunto com os demais alunos da disciplina.

Os dados coletados para esse estudo foram obtidos com os alunos que cursaram a disciplina de ESENC 1 no segundo semestre de 2017. No início do semestre estavam matriculados na disciplina 17 alunos, porém um aluno trancou a disciplina. Dessa forma os dados aqui apresentados são dos 16 alunos que concluíram a disciplina.

\section{Estratégias de Coleta de Dados}

A coleta de dados ocorreu em dois momentos, um no início e outro ao final do semestre. No primeiro dia de aula foi solicitado aos alunos que escrevessem, numa folha de caderno, seus medos e expectativas com relação ao estágio supervisionado de ensino, e cada um deles ficou livre para indicar a quantidade desses sentimentos que achasse pertinente. Depois de terem escrito o que sentiam, as folhas foram recolhidas e identificadas, sendo então realizada uma discussão sobre as indicações realizadas.

Ao final do semestre, após a realização de todas as atividades do estágio e à medida que os alunos entregavam seu portfólio de estágio, era enviado um e-mail ao aluno, com um arquivo contendo os medos e expectativas por ele indicados no início do semestre. Nesse momento era solicitado que ele escrevesse um texto, curto, a partir da reflexão sobre o que ele havia indicado no início do semestre e o que ele pensava sobre essas indicações após o término do estágio. Para fins de análise dos dados e com o intuito de manter em sigilo a identidade dos alunos participantes, cada um deles recebeu um nome fictício, identificando assim suas indicações e sua reflexão final.

\section{Análise dos dados}


A análise dos dados foi baseada na metodologia da análise conteúdo (BARDIN, 2011), onde inicialmente foi realizada uma leitura das expectativas e medos indicados pelos alunos e a partir dessa foram agrupadas. Esses agrupamentos foram definidos de acordo a quem estava endereçado aquele sentimento descrito pelo aluno, se ao próprio estagiário, aos alunos (da escola), aos professores (da escola) ou à escola. A partir dessa organização procurou-se identificar aspectos de destaque dentro de cada agrupamento e foram assim criadas as seguintes categorias: Ações/Fazeres, Aceitação/Relacionamentos, Validação/Confirmação, explicadas a seguir:

-Ações/Fazeres: quando o sentimento está de alguma forma ligado ao ato de realizar alguma coisa ou a alguma ação específica, direcionada ao próprio estagiário;

- Aceitação/Relacionamentos: direcionada à forma de se relacionar ou mesmo de como aos estudantes da escola, os professores da escola ou à própria escola irão aceitar a sua presença;

-Validacão/Confirmação: sentimento direcionado aos próprios estagiários, de forma a confirmar ou mesmo validar a decisão de se tornarem professores.

Os registros da reflexão dos alunos ao final do semestre sobre as expectativas e medos foram analisados de forma a verificar como o estágio contribui ou não para o enfrentamento desses sentimentos.

\section{Resultados e Discussão}

Os estudantes indicaram mais medos que expectativas no primeiro dia de aula quanto à realização do ESENC1. Em média cada alunos indicou 4-5 expectativas e 5-6 medos, totalizando 63 expectativas e 72 medos. Muitos compartilham as mesmas expectativas e medos, mas alguns apresentam questões bem pessoais, como por exemplo uma aluna que indicou que tinha medo de cair na frente da turma. 
A partir da análise das indicações percebemos que o momento de estágio realmente é cercado de muita tensão e apreensão, parecendo para muitos algo como o "grande teste", um desafio para se passar de fase (como num jogo) ou mesmo um ritual de passagem. A seguir serão apresentados alguns trechos que os alunos indicaram como expectativas e medos antes de começarem o ESENC 1.

\section{Ações e Fazeres}

Os sentimentos dos estagiários quanto ao estágio são muito direcionados a eles próprios, com cobranças pessoais muito grandes. Eles esperam realizar ações que muitas vezes não dependem somente deles e temem falhar no desempenho de suas atividades. Abaixo algumas citações que exemplificam essas situações:

"Medo de gaguejar" (Liz)

"Conseguir realizar tudo que foi planejado" (Marcos)

"Conseguir fazer com que os alunos entendam o que foi levado por mim e que esse conhecimento seja levado para fora da sala de aula" (Felipe)

O medo de gaguejar, indicado por Liz, pode estar relacionado a alguma situação que ela já tenha passado envolvendo estresse ou pressão e que ela tenha de alguma forma, medo de viver essa experiência negativa novamente. Já as indicações de Marcos e Felipe podem não dependem somente deles, no caso de Marcos, por exemplo, muitas vezes na escola não conseguimos realizar tudo que planejamos por motivos que as vezes saem do nosso alcance, como atividades paralelas realizadas pela escola e que acabam interferindo no quantitativo ou mesmo no tempo da aula.

Para Timostsuk e Ugaste (2012) sentimentos ou emoções relacionadas ao estágio desempenham papel fundamental na construção da identidade 
docente, tendo aqueles sentimentos ou experiências negativas, um impacto muito marcante na construção dessa identidade. Dessa forma o medo de não conseguir ou falhar é muito forte nos alunos, expondo de maneira bem clara o temor de vivenciar uma experiência negativa. Os trechos abaixo reforçam essa afirmação:

\author{
"Falhar em aulas propostas." (Paulo) \\ “Ter um desempenho considerável.” (Ana) \\ "Não conseguir envolver os alunos nas aulas." (Ana)
}

Essas inseguranças quanto às suas ações podem estar relacionadas a própria inexperiência dos estagiários como sugere Martinu, Souza e Gomesda-Silva (2013), já que para a grande maioria, o estágio realmente é a primeira experiência diante de alunos em uma escola, mesmo que alguns já podem ter tido alguma experiência como docente em projetos ou outra disciplina.

Dessa forma, os estudantes criam uma grande expectativa de colocar em prática, aplicar ou compartilhar algo que aprenderam ao longo de sua formação, seja um conteúdo, uma estratégia ou mesmo uma atitude:

“Colocar em prática as teorias de ensino-aprendizagem estudadas no curso, de modo que eu consiga fazer diferença no aprendizado dos meus alunos" (Márcia)

"Quero aplicar algumas técnicas que aprendi em Tópicos com o Valmir ${ }^{3}$ para ajudar" (Paulo)

"Ensinar os alunos a pensarem e mostrar a eles que eles são pensantes e não acumuladores de matéria, ensinar eles a questionarem" (Marcos)

Para Márcia e Paulo o estágio criou uma expectativa de aplicação de saberes aprendidos ao longo da formação, sendo que para Marcos é uma

\footnotetext{
${ }^{3}$ Valmir é o nome fictício de um professor da Faculdade UnB Planaltina.
} 
oportunidade de compartilhar ao que foi significativo para ele. Pimenta e Lima (2006) afirmam que esse momento de mobilização de saberes oriundos de disciplinas ou outros momentos de formação é extremamente importante, pois de forma geral esses saberes são desenvolvidos desvinculados para a atuação profissional.

Essa expectativa de aplicar e compartilhar saberes é seguida em muitos casos pelo medo de falhar, como podemos constar pelos trechos abaixo:

\footnotetext{
"Preocupação em não conseguir passar aquela matéria para os alunos como estava em mente" (Marcos)

"De não conseguir atingí-los e que eles saiam da minha sala sem saber nada" (Maria)

"Perceber que os alunos não aprenderam" (Mateus)
}

O medo de não conseguir dominar ou realizar algo ou de decepcionar alguém pode estar relacionado com a imaturidade dos estagiários, pois todos são muito jovens, outra questão que pode interferir nessa insegurança pode ser a sua inexperiência enquanto docente, sendo esses fatores citados em diversos trabalhos (LIMA, 2010; HONG; GREENE, 2011; MARTINU, SOUZA; GOMES-DA-SILVA, 2013; SHOYER; LESHEM, 2016). Possibilitar que os alunos se insiram na escola antes do estágio através de projetos ou disciplinas pode não só minimizar esses sentimentos, mas também encorajálos a ousar mais durante o estágio, permitindo que eles apliquem, testem e validem saberes aprendidos ao longo dos semestres do seu curso.

\section{Aceitação/Relacionamentos}

A aceitação direcionada aos alunos, professores e à própria escola também é motivo de apreensão por parte dos estagiários. Os trechos abaixo demonstram essa preocupação: 


\footnotetext{
"Como a escola e os alunos irão me receber" (Emília)

"Não ser bem recebido pela comunidade escolar" (João)

"Não ter boa interação no ambiente escolar" (Felipe)
}

Sendo que esse sentimento leva a uma grande expectativa de aceitação:

\begin{abstract}
"Conseguir fazer com que os alunos interajam bem comigo" (Afonso)

"Conseguir me conectar com os alunos, por ter uma aproximação mais de idade e talvez até gostos" (Rogério)

"Desenvolver uma boa relação com o professor responsável pela turma" (Mateus)
\end{abstract}

Possivelmente esses sentimentos de receptividade e relacionamento fazem parte do imaginário dos alunos de que um bom professor, é aquele querido ou que se relaciona bem com seus alunos. Para Shoyer e Leshem (2013) essa idealização de um bom professor é motivadora de expectativas e medos quanto à atuação deles como docentes. Porém, os estagiários esquecem que essa relação com os alunos deve ser construída dia a dia e isso pode levar um tempo. Talvez durante o estágio isso não seja possível pelo tempo limitado de atuação.

Para alguns estagiários, o bom relacionamento com os alunos depende de uma relação de respeito entre eles, indicando que para isso a disciplina é fundamental, sentimento semelhante encontrado por Hong e Greene (2011). Alguns trechos abaixo representam essa afirmação:

"Não conseguir impor respeito, pelo fato de não parecer tão velho/adulto, que é o que as crianças mais respeitam.” (Rogério) "Não controlar a turma e a aula se tornar uma anarquia". (Marta) "De não ter moral e não ser respeitada" (Maria) 


\section{Validação/Confirmação}

Alguns autores já indicaram que o estágio pode ajudar a confirmar ou não o desejo de ser professor por parte dos estagiários (SCHUTZ; CROWDER; WHITE, 2001; ZANCUL, 2011; ROTTA; FRANÇA, 2018), confirmando o sentimento de muitos alunos que identificam o estágio como um "grande teste" para a carreira docente, acreditando que se "passarem" terão a certeza que fizeram a escolha certa ao entrarem num curso de licenciatura. Os trechos abaixo demonstram esse sentimento:

\footnotetext{
"Descobrir se serei professora." (Priscila)

"Espero poder descobrir se estou mesmo seguindo o caminho correto." (Camila)

"Conseguir ter maior certeza que é essa a profissão que realmente quero seguir, principalmente por ser a melhor coisa que eu acredito fazer.” (Felipe)
}

Apesar de concordar que o estágio seja uma experiência importante no processo de formação, ele não é a única, pois eles irão realizar outros estágios. Além disso, os primeiros anos de trabalho como docente também podem contribuir para essa decisão.

Corroborando essa ideia de "teste", os estagiários entendem que caso não "passem", fizeram uma escolha errada:

\footnotetext{
"Descobrir que a profissão "não é para mim" e acabar desistindo de algo que acredito tanto.” (Felipe)

"Descobrir que não nasci para isso." (Maria)
}

O estágio possui esse estigma de rito de passagem para carreira docente, porém, apesar da sua importância ele não é o único responsável por formar um professor. O momento do estágio é realmente um momento que 
mobiliza vários destes saberes e possibilita, com o exercício na prática, o desenvolvimento de outros. Porém, como dito acima, esse momento não é único, o professor em formação terá outros momentos como esse ao longo de sua trajetória, como outros estágios ou até mesmo os primeiros anos de sua carreira como docente. Um resultado não satisfatório, do ponto de vista do aluno, ou até mesmo os satisfatórios não comprovam ou confirmam nada, apenas indicam ações, posturas ou estratégias que devem ser mantidas ou repensadas, por isso a importância desse momento ser um momento reflexivo.

Esse momento de imersão e reflexão não deve ser um momento solitário, o professor regente na escola assim como o professor responsável pela disciplina na instituição de ensino superior deve orientar e promover a reflexão sobre as questões emergentes no estágio, ajudando-o nas dificuldades encontradas e no enfrentamento de medos e angústias sobre a carreira docente.

\section{Reflexão após o estágio}

No decorrer do semestre muitas dessas expectativas e medos foram abordadas ao longo da disciplina, algumas vezes trazidas pelos próprios alunos e outras pelo próprio professor responsável pela disciplina. Ao final da disciplina, conforme descrito na metodologia, os alunos entregaram uma reflexão sobre os sentimentos que eles indicaram no início do semestre.

$\mathrm{Na}$ maioria das situações eles indicaram que as expectativas e medos se concretizaram de alguma forma, mas que passar por isso, enfrenta-los e em muitas situações superá-los foi importante. Abaixo alguns exemplos:

"Ao observar os medos e expectativas que eu tinha no começo do semestre posso confirmar que vivi cada um deles, porém, todos superados e que deram espaço a outros medos e expectativas que futuramente quero também passar por todos eles.” (Ana). 
"Meus medos e expectativas permaneceram os mesmos ao longo do estágio, consegui vencer meus medos e percebi que não passavam de bobagens e que eu preciso confiar mais em mim mesma." (Maria)

"Realmente os medos se tornaram realidade... uns mais que outros, mas nada que me atrapalhasse.” (Priscila)

Os exemplos trazidos acima reforçam a importância de vivenciar a experiência do estágio, encontrando situações reais e através delas enfrentar seus medos e expectativas, uma vez que a experiência dá confiança aos estagiários para enfrentar essas e outras situações semelhantes (TULI, 2009)

Para muitos alunos essa superação está diretamente relacionada com a prática:

"Realmente no estágio as três primeiras coisas que coloquei aconteceram e muitas outras expectativas surgiram, pois me proporcionou um aprendizado diferente do que estou acostumada, foi muita prática e eu acho que é isso mesmo que a gente precisa, prática. Estágio tem que ser feito na escola sim, para nós deixarmos nossos medos de lado.” (Liz).

"Como eu disse antes, novas expectativas e medos vão surgindo no decorrer da prática, mas no final deu tudo certo.” (Paulo)

"Com base nas expectativas e medos antes de iniciar o estágio, posso dizer seguramente que os medos foram eliminados no decorrer da regência, pois foi de grande valia estar tão próxima dos alunos, poder conhecer a dificuldade de alguns [...]” (Camila)

Nóvoa (2009) destaca a importância da profissão docente ser construída dentro dela própria, com o estudo de situações reais e reflexão sobre a prática dos professores. O estágio permite que os alunos vivenciem essas situações reais e reflitam sobre suas ações, possibilitando dessa forma, a construção e a desconstrução de crenças e outros sentimentos. 
Conhecer e passar pelas situações mostrou para os alunos que elas são superáveis ou até mesmo que não deveriam gerar tantas apreensões:

"A aprendizagem dos alunos foi algo que gerou em mim a maior inquietação, pois se eles não estivessem aprendendo para mim não teria adiantado de nada ter aplicado aquelas aulas. Mas compreendi que muitas das vezes o aluno tem que ser o maior interessado em aprender." (João)

"Quanto aos medos, o principal era gaguejar, e aconteceu, mas não foi tão desesperador igual eu esperava." (Paulo).

"Após essa primeira experiência como regente de uma sala de aula, mesmo como estagiário, tem ainda mais certeza de que estou no caminho para ter a profissão que me dará uma grande satisfação em seguir." (João)

"Eu sempre me senti bastante inseguro quando não treinava com minha irmã antes, mas com o estágio, a hora que eu tinha que sair ela estava no curso, então eu muitas vezes treinava no ônibus voltando do trabalho ou até mesmo em frente ao espelho, entretanto lá pra quinta aula, eu nem treinei, e só percebi isso depois da aula. A sensação foi de libertação, autoconfiança." (Paulo)

"Os meus medos, no geral, foram superados e eram bobos. Esses medos é o normal de todo ser humano. Medo de não dar o conteúdo planejado? Para isso que existe plano A, B, C, D, E.....W, A1, B1 etc." (Marcos)

Para alguns a experiência trouxe algumas certezas, mas para outras ainda não:

"[...] me fez enxergar que é esse o caminho que quero mesmo seguir." (Camila) 
“[...] se antes eu não tinha ideia do que eu queria seguir como profissão hoje eu tenho a mais plena certeza ser professor e ser por amor e por expectativas de um futuro melhor.” (Bruna)

"A única coisa que não consegui saber ainda é confirmar se eu quero ser professora mesmo." (Liz)

Pelos trechos acima transcritos podemos perceber que a experiência do estágio realmente passou pelos alunos, ela aconteceu mesmo neles como indicou Larrosa (2005, 2011). Esses estudantes, em sua maioria, se permitiram sentir e experimentar, sofrer e levantar, acertar e errar durante o estágio, o que possibilitou a eles transformações neles, em suas ações, sentimentos e palavras (LARROSA, 2011). Essa experiência influencia diretamente outros saberes desenvolvidos pelos alunos ao longo de sua formação, validando-os ou modificando-os com base na experiência (TARDIF, 2014).

\section{Conclusão}

As experiências promovidas pelos estágios supervisionados nos cursos de licenciaturas, como o aqui apresentado, vão além da formação docente, em muitos casos são experiências para a vida. Muitos alunos, além dos sentimentos relacionados à carreira docente, trazem também sentimentos particulares, oriundos de outras situações fora do meio acadêmico, mas que podem ser importantes na construção da sua identidade como docente. Enfrentar esses sentimentos no contexto escolar pode ser determinante para sua decisão quanto à carreira e o seu futuro como professor.

Porém, esse enfrentamento não deve ser solitário e sem planejamento. Professores supervisores de estágio, tanto da universidade quanto da escola são participantes ativos desse processo e devem conhecer esses sentimentos, sejam através de dinâmicas e outras atividades realizadas com os 
estagiários ou do diálogo e compartilhamento entre esses dois espaços, universidade e escola. Essa troca de informações entre esses espaços de formação irá contribuir para estreitar relações e ajudar os estagiários na construção de suas identidades como docentes, pois baseado nessa troca, ações coordenadas podem ser planejadas ao longo dos processos de formação.

\section{Referências}

BACCON, A. L. P.; ARRUDA, S. M. Os saberes docentes na formação inicial do professor de física: elaborando sentidos para o estágio supervisionado. Ciência e Educação, 16(3): 507-524. 2010.

BARDIN, L. Análise de conteúdo. São Paulo: Edições 70. 2011.

BARRETO, E. S.; OLIVEIRA, M. M.; ARAÚJO, M. L. F. Pontos positivos e negativos do estágio supervisionado na perspectiva dos licenciandos em Ciências Biológicas. Enseñanza de las Ciencias, Extra: 297-301. 2013.

BATES, A. J.; RAMIREZ, L.; DRITS, D. Connecting university supervision and critical reflection: Mentoring and modeling. The Teacher Educator, 44(2), 90-112. 2009.

BECK, C.; KOSNICK, C. Components of a good practicum placement: Student teacher perceptions. Teacher Education Quarterly, 29(2), 81-98. 2002.

BULLOUGH, R. V. JR.; YOUNG, J.; ERICKSON, L.; BIRRELL, J. R., Clarck, D. C., Egan, M. W., et al. Rethinking field experience: Partnership teaching versus single-placement teaching. Journal of Teacher Education, 53(1), 68-80. 2002.

CHAPLAIN, R. P. Stress and psychological distress among trainee secondary teachers in England. Educational Psychology, 28(2), 195-209. 2008.

FEIMAN-NEMSER, S. From preparation to practice: design a continuum to strengthen and sustain teaching. The teacher S. College Record, 103: 1013-1055. 2001.

HONG, J.; GREENE, B. Hopes and fears for science teaching: the possible selves of preservice teachers in science education program. Journal of Science Teacher Education, 22(6): 491-512. 2011.

KOC, I. Preservice science teachers reflect on their practicum experiences. Educational Studies, 38(1): 31-38. 2012. 
LARROSA, J. Notas sobre a experiência e o saber da experiência. Revista Brasileira de Educação, 19: 20-28. 2005.

(_ (_) Experiência e alteridade em Educação. Revista Reflexão e Ação, 19(2): 427. 2011.

LESHEM, S.; TRAFFORD, V. N. Stories as mirrors: reflective practice in teaching and learning. Reflective Practice, 7: 0-27. 2006.

LIMA, F. S. Beliefs about being an English teacher: hopes and fears. Belt Journal, 1(21): 106-120. 2010.

LINDQUIST, H.; WEURLANDER, M.; WERNERSON, A.; THORNBERG, R. Resolving feelings of professional inadequacy: student teachers' coping with distressful situations. Teaching and Teacher Education, 64: 270-279. 2017.

MARCELO, C. O professor iniciante, a prática pedagógica e o sentido da experiência. Formação Docente, 2(3): 11-49. 2010.

MARTINU, L.; SOUZA, I.; GOMES-DA-SILVA, P. Como saber se meu mundo de ideias daria certo na prática: o medo da docência no estágio supervisionado em educação física. Motrivivência, 40: 51-66. 2013.

MINISTÉRIO DA EDUCAÇÃO BRASIL. Parecer CNE/CP 28/2001. Conselho Nacional de Educação, Brasília, 2001. Disponível em: http://portal.mec.gov.br/cne/arquivos/pdf/028.pdf . Acesso em: 20 set. 2018.

MINISTÉRIO DA EDUCAÇÃO BRASIL. Resolução no. 2, de 1o. de julho de 2015. Diretrizes Curriculares Nacionais para a formação inicial em nível superior (cursos de licenciatura, cursos de formação pedagógica para graduados e cursos de segunda licenciatura) e para a formação continuada. Conselho Nacional de Educação, Brasília, 2015. Disponível em: http://portal.mec.gov.br/docman/agosto-2017pdf/70431-res-cne-cp-002-03072015-pdf/file. Acesso em: 20 set. 2018.

NÓVOA, A. Professores: imagens do futuro presente. Lisboa, Educa, 95p.

Parkison, P. T. (2008). Field placement treatments: A comparative study. The Teacher Educator, 43(1), 29-45. 2009.

PEREIRA, D. C.; OVIGLI, D. F. B. Estágio supervisionado: relatos do processo de constituição da identidade docente em Uberaba-MG. Revista Profissão Docente Online, 17(37): 51-62. 2017.

PIMENTA, S. G.; LIMA, M. S. L. Estágio e docência: diferentes concepções. Revista Poíesis, 3 (3-4): 5-24. 2006.

RAZUCK, R. C. S. R.; ROTTA, J. C. G. O Curso de licenciatura em Ciências Naturais e a organização de seus estágios supervisionados. Ciência \& Educação, 20(3), 739-750. 2014. 
ROTTA, J. C. G; FRANÇA, R. S. A formação reflexiva do professor de ciências naturais e o estágio supervisionado. Revista Electrónica de Enseñanza de las Ciencias, 17(2): 509-571. 2018.

SCHUTZ, P. A.; CROWDER, K. C.; WHITE, V. E. The development of a goal to become a teacher. Journal of Education Psychology, 93: 299-308. 2001.

SHOYER, S.; LESHEM, S. Students' voice: the hope and fears of student-teacher candidates. Cogent Education, 3: 1-12. 2016

SILVA, D. M. S.; PEDREIRA, A. J. A percepção dos alunos estagiários licenciandos em Ciências Naturais do papel dos professores supervisores da escola. Revista Electrónica Enseñanza de las Ciencias, 15(3): 412-427. 2016.

SMITH, K.; LEV-ARI, L. The place of practicum in preservice teacher education: The voice of the students. Asia-Pacific Journal of Teacher Education, 33(3), 289302. 2005.

TARDIF, M. (2014) Saberes docentes e formação profissional. Petrópolis, Vozes, 325p. 2014.

TIMOSTSUK I.; USGATE, A. The role emotions in student teacher's professional identity. European Journal of Teacher Education, 35: 421-433. 2012.

TULI, F. Understanding undergraduate students' practicum experience: a qualitative case study of Jimma University. Ethiop. J. Educ. and Sci., 5(1): 37-60. 2009 .

VAN VEEN, K.; SLEEGERS, P.; VAN DE VEN, P. One teacher's identity, emotions, and commitment to change: A case study into the cognitive-affective process of a secondary school teacher in the context reforms. Teaching and Teacher Education, 21: 917-934. 2005.

ZANCUL, M. S. O estágio supervisionado de ensino segundo a percepção de licenciandos em Ciências Biológicas. Revista Simbio-logias, 4(6): 24-35. 2011. 